\title{
Expression of epidermal growth factor-like domain 7 may be a predictive marker of the effect of neoadjuvant chemotherapy for locally advanced uterine cervical cancer
}

\author{
MAKOTO YAMAUCHI, TAKESHI FUKUDA, TAKUMA WADA, MASARU KAWANISHI, \\ KENJI IMAI, REIKO TASAKA, TOMOYO YASUI and TOSHIYUKI SUMI
}

Department of Obstetrics and Gynecology, Osaka City University Graduate School of Medicine, Osaka 545-8585, Japan

Received September 7, 2015; Accepted August 26, 2016

DOI: $10.3892 / 01.2016 .5318$

\begin{abstract}
Neoadjuvant chemotherapy (NAC) followed by hysterectomy may be effective for the treatment of locally advanced uterine cervical cancer and improve patient prognosis. It is important to identify markers that are able to predict whether NAC may be successful. Epidermal growth factor-like domain 7 (EGFL7) regulates vascular sprouting in blood vessel formation. In numerous types of human cancer, EGFL7 is upregulated and inhibits endothelial cell adhesion molecules, decreasing vascular tightness and, thus, increasing vascular permeability. It is considered that the overexpression of EGFL7 is able to inhibit drug delivery, resistance to apoptosis and the epithelial-to-mesenchymal transition. In the current study, 63 patients with locally advanced uterine cervical cancer were reviewed and classified as stage IIIA-IIIB using the International Federation of Gynecology and Obstetrics criteria. These patients (aged $<70$ years) were treated at Osaka City University Medical School Hospital, Japan, between 1995 and 2010. Tumor tissue samples were obtained by biopsy prior to NAC. The tissue samples were classified as group 1 or 2 depending on the efficacy of NAC. Surgery and radiotherapy were administered in group $1(n=36)$, for which NAC was effective. In the patients of group 2 NAC was not effective, and radiotherapy alone was administered $(n=27)$. The expression of EGFL7 and Snail was examined in paraffin-embedded tissue sample sections using the avidin-biotin peroxidase complex method. The results indicated that EGFL7 expression levels were significantly higher in group 2, as compared with group $1(\mathrm{P}<0.001)$. A similar result was observed for the expression levels of Snail $(\mathrm{P}=0.001)$. Group 1 exhibited significantly longer overall survival times compared with group $2(\mathrm{P}=0.001)$. The
\end{abstract}

Correspondence to: Dr Takeshi Fukuda, Department of Obstetrics and Gynecology, Osaka City University Graduate School of Medicine, 1-4-3 Asahimachi, Abeno-ku, Osaka 545-8585, Japan E-mail: takeshif@med.osaka-cu.ac.jp

Key words: uterine cervical cancer, epidermal growth factor-like domain 7, Snail, neoadjuvant chemotherapy, predictive marker patients were also classified into a low EGFL7 expression level group (weighted score of $\leq 6$ ) and a high EGFL7 expression level group (weighted score of $\geq 8$ ). NAC was observed to be significantly more effective in the low EGFL7 expression level group $(\mathrm{P}<0.001)$, as compared with the high expression level group. The results suggest that the expression levels of EGFL7 may be a potential predictive marker of the efficacy of NAC for the treatment of locally advanced uterine cervical cancer.

\section{Introduction}

Cervical cancer is a frequent cause of cancer-associated mortality in females worldwide (1). The current treatments for cervical cancer vary, and the treatment of locally advanced uterine cervical cancer, including International Federation of Gynecology and Obstetrics (FIGO) (2) stage IIIA (in which the tumor involves the lower third of the vagina with no extension to the pelvic wall), IIIB (in which the tumor extends to the pelvic wall and causes hydronephrosis or a nonfunctioning kidney) and IVA (in which the tumor invades the mucosa of the bladder or rectum, and extends beyond the true pelvis) is challenging as locally advanced cervical cancer is inoperable $(3,4)$. Concurrent chemoradiotherapy is the standard treatment for locally advanced uterine cervical cancer $(3,4)$; however, the prognosis of patients is typically poor, with 5-year survival rates of $\sim 60 \%(5,6)$. A previous study reported that prognosis may improve if neoadjuvant chemotherapy (NAC) is successful in treating locally advanced uterine cervical cancer (7). However, the prognosis worsens if NAC is not effective, as hysterectomy cannot be performed if downstaging by NAC is not achievable. Subsequently changing the treatment plan from surgery to radiotherapy may result in a fatal delay for the patient $(8,9)$.

The availability of specific predictive markers for the effectiveness of NAC would facilitate the identification of patients with positive predictive markers and allow them to be effectively treated with NAC. However, no significant predictive markers of NAC efficacy are currently available for locally advanced uterine cervical cancer. Thus, it is essential to identify such markers (10-14).

Epidermal growth factor-like domain 7 (EGFL7) is a secreted signaling factor derived from endothelial cells (15). The EGFL7 gene encodes a $30-\mathrm{kDa}$ protein that includes a 
signal peptide and two epidermal growth factor-like domains, and is located on chromosomes 2 and 9 in mice and humans, respectively (16). EGFL7 is upregulated during angiogenesis and is involved in the regulation of endothelial cell migration during the sprouting process, blood vessel lumen formation and maintenance of vascular integrity (17-19). In certain types of human cancer cells, EGFL7 inhibits the activity of endothelial cell adhesion molecules [such as vascular cell adhesion molecule 1 (VCAM1) and intercellular adhesion molecule 1 (ICAM1)], which leads to decreased vascular tightness (increased vascular permeability), increased immune evasion and increased tumor growth (20). Decreased blood vessel integrity is frequently observed in malignant tumors (21). Furthermore, poor perfusion of tissues inhibits drug delivery in malignant tumors; abnormal vasculature of tumors and the resulting abnormal microenvironment together pose a formidable barrier to the delivery and efficacy of cancer therapy. A previous study revealed that EGFL7 is highly expressed in human epithelial tumor tissues, including hepatocellular carcinoma, lung cancer, breast cancer, gastric cancer, colorectal cancer, prostate cancer, esophageal cancer, malignant glioma, ovarian cancer and renal cancer (22). Certain studies have reported that high expression levels of EGFL7 are associated with lymph node metastasis, poor prognosis and advanced disease stage in numerous types of human cancer, including colon cancer, pancreatic cancer, epithelial ovarian cancer and laryngeal squamous cell cancer (23-26). Luo et al (27) reported that the expression of EGFL7 in gastric cancer cells promotes the epithelial-to-mesenchymal transition (EMT) and tumor metastasis by epidermal growth factor receptor (EGFR)-mediated protein kinase B (AKT) phosphorylation, which subsequently activates Snail and suppresses the transcription of E-cadherin. Numerous studies have demonstrated that increased EMT may lead to chemoresistance in bladder, lung, breast and ovarian cancers (28-32). In addition, Vega et al (33) reported that Snail inhibits the cell cycle and confers resistance to TGF- $\beta$-induced cell death, consistent with Snail activating the Mek/Frk and PI3K/Akt survival pathways.

To the best of our knowledge, the present study is the first to examine EGFL7 expression in uterine cervical cancer cells. It was hypothesized that EGFL7 may have a role in the development of acquired chemoresistance through lowered drug delivery, increased EMT and increased cell resistance to apoptosis due to the downstream activation of Snail. EGFL7 may also be a prognostic factor for the efficacy of NAC in locally advanced cervical cancer. Therefore, the current study investigated whether EGFL7 expression levels are associated with the efficacy of NAC for locally advanced uterine cervical cancer.

\section{Materials and methods}

Patients and samples. Eligible patients were aged $<70$ years, had histologically confirmed primary stage IIIA and IIIB cancer of the uterine cervix, and underwent NAC; the patients were treated at the Osaka City University Medical School Hospital (Osaka, Japan) between 1995 and 2010. Exclusion criteria included the lack of informed consent, the unavailability of the tumor samples, and the patient not undergoing NAC. The tumor samples were obtained through a punch
Table I. Clinical characteristics of patients in group 1 $(\mathrm{NAC}+\mathrm{OP}+\mathrm{R})$ and group $2(\mathrm{NAC}+\mathrm{R})$.

\begin{tabular}{lccr}
\hline Characteristic & NAC+OP+R & NAC+R & P-value \\
\hline $\begin{array}{l}\text { No. of patients } \\
\text { Age (years) }\end{array}$ & 35 & 27 & \\
Mean \pm SD & $49.3 \pm 12.7$ & $52.3 \pm 11.1$ & \\
Range & $24-69$ & $36-68$ & \\
FIGO stage & & & $0.322^{\mathrm{a}}$ \\
IIIA & 1 & 0 & \\
IIIB & 34 & 27 & \\
Histology & & & $0.436^{\mathrm{b}}$ \\
SCC & 30 & 22 & \\
A & 5 & 3 & \\
AS & 0 & 1 & \\
Other & 0 & $1^{\mathrm{c}}$ & \\
Tumor size & $46.9 \pm 17.2$ & $53.7 \pm 14.9$ & $0.144^{\mathrm{a}}$ \\
(mm; mean \pm SD) & & & \\
\hline
\end{tabular}

${ }^{a}$ Student's t-test; ${ }^{\mathrm{b}} \chi^{2}$ test; ${ }^{\mathrm{c}}$ glassy cell carcinoma. NAC+OP+R, neoadjuvant chemotherapy, surgery and radiotherapy; NAC+R, neoadjuvant chemotherapy and radiotherapy only; FIGO, International Federation of Gynecology and Obstetrics; SCC, squamous cell carcinoma; A, adenocarcinoma; AS, adenosquamous carcinoma; SD, standard deviation.

biopsy prior to the administration of NAC. Patients were divided into groups 1 and 2 depending on the effectiveness of NAC. Group 1 consisted of those patients who effectively responded to NAC, resulting in downstaging to an operable condition, and who subsequently underwent surgery and radiotherapy ( $n=36)$. Group 2 consisted of those patients who were unsuccessfully treated with NAC, resulting in ineligibility for hysterectomy, and who subsequently received radiotherapy only $(n=27)$. Written informed consent was obtained from all patients prior to the tumor biopsy. The Ethics Committee of Osaka City University approved the current study protocol (IRB no. 2859, 3078).

Balloon-occluded arterial infusion chemotherapy (BOAI) for $N A C$. A pelvic angiography was performed under local anesthesia (34) in order to locate the tumor and the feeding vessels. A balloon-wedge single-pressure catheter was inserted $(5 \mathrm{~F}$, $80 \mathrm{~cm}$ in length; Dispomedica, Hamburg, Germany) from each femoral artery into the internal iliac artery; the balloon catheters were advanced until in proximity to the feeding vessel, which was usually the uterine artery, and then inflated in order to occlude the local blood flow. Cis-diamminedichloro-platinum (CDDP; Bristol-Myers Squibb Company, New York, NY, USA) was intra-arterially infused through the two catheters over $30 \mathrm{~min}$ (34). In the current study, the two ovarian arteries were blocked following the initial BOAI procedure in order to increase the concentration of CDDP near the tumor. BOAI was performed three times to reduce the size of the tumor. Abundant hydration, for the preservation of renal function, was performed prior to and following CDDP administration, 

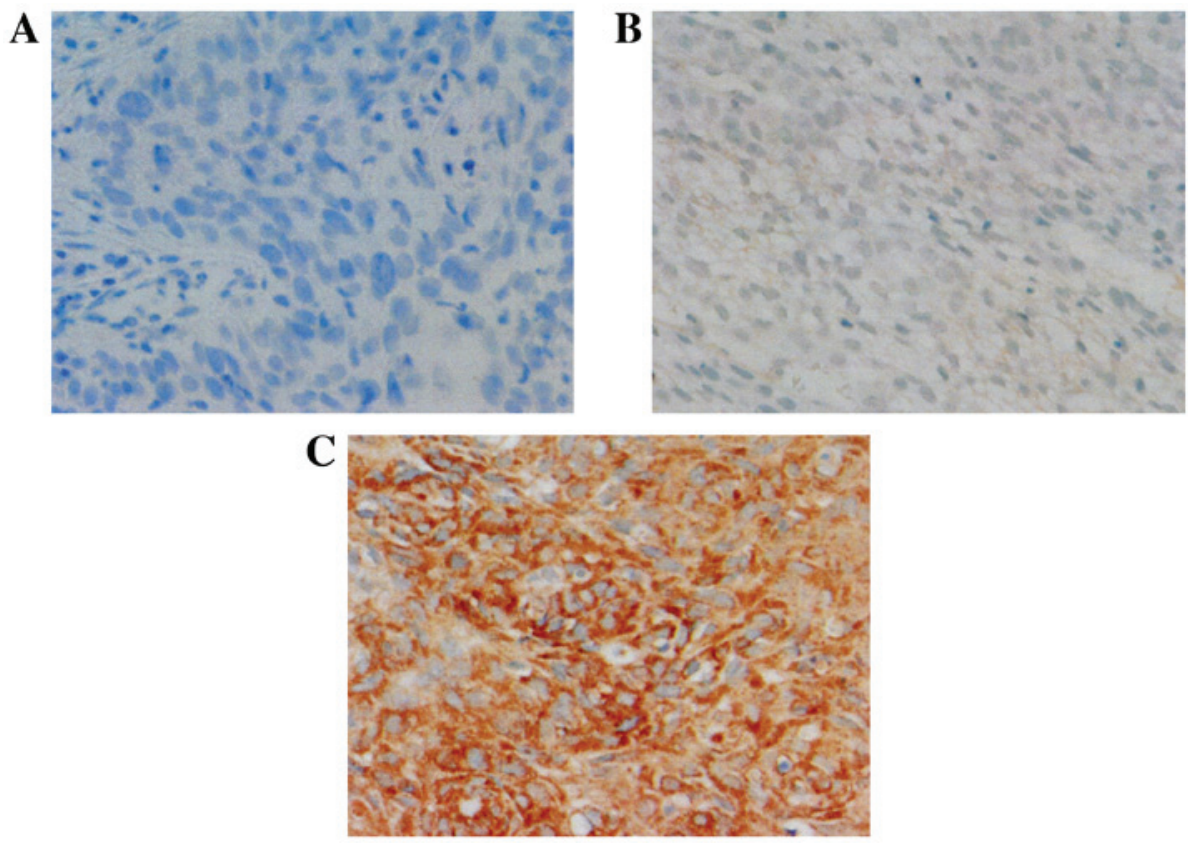

Figure 1. Immunohistochemical staining of EGFL7 in locally advanced uterine cervical cancer tissue samples. (A) Negative controls without the primary antibody; (B) weighted score 1, group 1; (C) weighted score 12, group 1. Cells were counterstained with hematoxylin; magnification, x400. EGFL7 expression was observed in the cytoplasm of the tumor cells. EGFL7, epidermal growth factor-like domain 7.

and antiemetics and diuretics were used appropriately. CDDP was administered at doses of 50,75 or $100 \mathrm{mg} / \mathrm{m}^{2}$, according to the patient's age and renal function. Magnetic resonance imaging (MRI) was used to assess the rate of tumor reduction by evaluating its maximum dimensions $(35,36)$.

Immunohistochemical analysis. The expression patterns of EGFL7 and Snail were examined in paraffin-embedded tissue sections using a monoclonal mouse anti-human EGFL7 antibody (\#sc-101349; Santa Cruz Biotechnology, Inc., Dallas, TX, USA; dilution, 1:500), a polyclonal rabbit anti-human Snail antibody (\#13099-1-AP; ProteinTech Group, Inc., Chicago, IL, USA; dilution, 1:100) and a Dako LSAB2 peroxidase kit (\#K0675; Dako Japan Co., Ltd., Tokyo, Japan), according to the manufacturer's instructions. Paraffin-embedded tissue sections $(4 \mu \mathrm{m})$ were deparaffinized, rehydrated and immersed in $3 \%$ hydrogen peroxide for $10 \mathrm{~min}$ at room temperature to block endogenous peroxidase activity. An antigen retrieval procedure was performed by immersing the tissue sections in $10 \mathrm{mM}$ citrate buffer ( $\mathrm{pH}$ 6.0) and heating in an autoclave at $110^{\circ} \mathrm{C}$ for $20 \mathrm{~min}$. The tissue sections were then washed in phosphate-buffered saline (PBS). The tissue sections were incubated overnight with anti-EGFL7 or anti-Snail primary antibodies in a humidity chamber at $4^{\circ} \mathrm{C}$, washed with PBS for $15 \mathrm{~min}$, and then incubated for $10 \mathrm{~min}$ with biotinylated goat anti-mouse and anti-rabbit immunoglobulin G secondary antibodies (Dako Japan Co., Ltd). The tissue sections were then incubated with a streptavidin-peroxidase complex and 3,3'-diaminobenzidine was used as the chromogen. The sections were counterstained with Mayer's hematoxylin and the specificity of the immunohistochemical reactions was determined by omitting the primary antibody. The expression levels of EGFL7 or Snail were quantitatively analyzed using the scoring method of Sinicrope et al (37). Five individual fields were imaged for each tissue specimen (magnification, $\mathrm{x} 400$ ). The tissues were classified into five categories according to the mean proportion of positive tumor cells, as follows: 0 , $<5 \% ; 1,5-25 \% ; 2,25-50 \% ; 3,50-75 \% ; 4,>75 \%$. The intensity of the immunostaining was classified into three categories, as follows: $1+$, weak; $2+$, moderate; $3+$, intense. The weighted score was calculated by multiplying the percentage of positive tumor cells by the staining intensity for each tissue specimen.

Statistical analysis. The data are presented as the mean \pm standard deviation. Kaplan-Meier and log-rank tests were performed for prognostic analysis, based on overall survival rates. The weighted scores were compared using the Mann-Whitney U test. The Student's t-test and the $\chi^{2}$ test were performed as appropriate for intergroup comparisons. SPSS software version 21.0 (IBM SPSS, Armonk, NY, USA) was used for all statistical analyses. $\mathrm{P}<0.05$ was considered to indicate a statistically significant difference.

\section{Results}

Patient clinical characteristics. A total of 35 patients were assigned to group 1, and 27 to group 2, with mean ages of 49.3 years (range, 24-69 years) and 52.3 years (range, 36-68 years), respectively. Of the patients in group 1,1 patient was diagnosed with FIGO stage IIIA uterine cervical cancer and 34 patients were diagnosed with stage IIIB disease. Of the patients in group 2, all 27 were diagnosed with stage IIIB uterine cervical cancer. Histologically, the 35 patients of group 1 comprised 30 cases of squamous cell carcinoma and 5 of adenocarcinoma. In the patients of group 2, 22 had squamous cell carcinomas, 3 had adenocarcinomas, 1 had adenosquamous carcinoma and 1 had glassy cell carcinoma. There were no significant differences observed between the 
Table II. Weighted scores for epidermal growth factor-like domain 7 expression levels in group $1(\mathrm{NAC}+\mathrm{OP}+\mathrm{R})$ and group 2 (NAC+R).

\begin{tabular}{lcc}
\hline & \multicolumn{2}{c}{ No. of patients } \\
\cline { 2 - 3 } Weighted score & NAC+OP+R $(\mathrm{n}=35)$ & NAC+R $(\mathrm{n}=27)$ \\
\hline 0 & 5 & 0 \\
1 & 5 & 0 \\
2 & 8 & 2 \\
3 & 8 & 0 \\
4 & 4 & 2 \\
6 & 2 & 1 \\
8 & 1 & 6 \\
9 & 2 & 7 \\
12 & 4.11 & 9 \\
Mean score & 5.78 \\
\hline
\end{tabular}

$\mathrm{NAC}+\mathrm{OP}+\mathrm{R}$, neoadjuvant chemotherapy, surgery and radiotherapy; $\mathrm{NAC}+\mathrm{R}$, neoadjuvant chemotherapy and radiotherapy only.

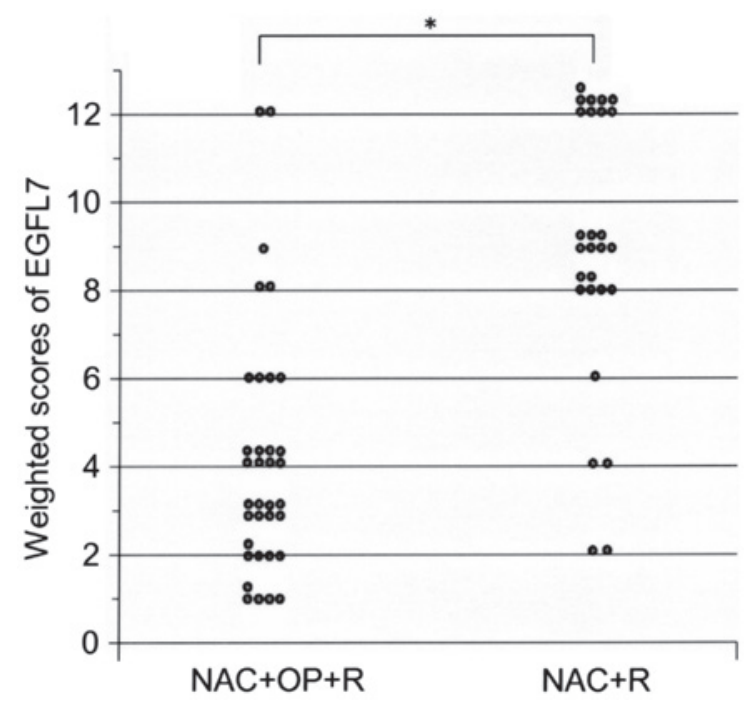

Figure 2. Weighted scores for EGFL7 expression levels in tumor tissue samples from patients with locally advanced uterine cervical cancer. EGFL7 expression levels were significantly higher in group $2(\mathrm{NAC}+\mathrm{R})$, as compared with group $1(\mathrm{NAC}+\mathrm{OP}+\mathrm{R})\left({ }^{*} \mathrm{P}<0.001\right.$ (Mann-Whitney U test). EGFL7, epidermal growth factor-like domain 7; NAC, neoadjuvant chemotherapy; OP, surgery; $\mathrm{R}$, radiotherapy.

two groups with regard to any of the recorded clinical characteristics (Table I).

Expression profile of EGFL7 in uterine cervical cancer tissues. The expression of EGFL7 was observed in the cytoplasm of the tumor cells (Fig. 1). Table II presents the weighted scores in the tissues of patients from group 1 and group 2. The mean weighted score of EGFL7 expression was significantly lower in group 1, as compared with in group 2 (4.1 vs. 8.8; $\mathrm{P}<0.001$; Fig. 2). Of all the patients involved, 35 exhibited low expression levels of EGFL7, with a weighted score of $\leq 6$, whereas
27 patients exhibited high expression levels of EGFL7, with a weighted score of 8-12. There were no significant differences in clinical characteristics observed between the low EGFL7 expression group and the high EGFL7 expression group (Table III).

Association between the expression of EGFL7 and the efficacy of NAC. Among the 35 patients with low EGFL7 expression, 30 patients (86\%) were in group 1 and 5 patients (14\%) were in group 2. With regard to high EGFL7 expression, 5/27 patients (19\%) were in group 1, while 22/27 (81\%) patients were in group 2 . This indicates that NAC was significantly more effective in the low EGFL7 expression group as compared with the high EGFL7 expression group ( $\mathrm{P}<0.001$; Table IV).

Expression profile of Snail in uterine cervical cancer tissues. The expression of Snail was observed in the nuclei of the tumor cells. The weighted expression scores are presented in Table V. The mean weighted score for Snail expression levels was significantly lower in group 1, as compared with in group 2 (4.7 vs. 9.4; P<0.001; Fig. 3).

Correlation between the expression of EGFL7 and Snail. Out of all the patients involved, 29 exhibited low expression levels of EGFL7 and of Snail, and 23 patients had high expression levels of EGFL7 and of Snail. A significant positive association was observed between the expression levels of EGFL7 and Snail (r=0.56; $\mathrm{P}<0.001$; Fig. 4).

Overall survival analysis. Kaplan-Meier and log-rank analyses indicated that the overall survival time was significantly longer in group 1 (patients who responded to NAC; mean, 3,257 days), as compared with group 2 (mean, 1,239 days; $\mathrm{P}=0.001$; Fig. 5). The overall survival time was also significantly longer in the low EGFL7 expression level group, as compared with the high EGFL7 expression level group $(\mathrm{P}=0.001$; Fig. 6).

\section{Discussion}

The results of the present study demonstrated a significant association between the expression levels of EGFL7 and the effectiveness of NAC in patients with locally advanced uterine cervical cancer at FIGO stage IIIA and IIIB; NAC was determined to be unsuccessful in the majority of patients with high EGFL7 expression levels, who were thus unable to undergo surgery and received only radiotherapy. Overall survival was significantly longer in group 1 patients (those for whom NAC had been successful), as compared with group 2 . These results are concordant with previous studies, which demonstrated that patient prognosis worsens when NAC is unsuccessful $(8,9)$. Similarly, overall survival time was significantly longer in the low EGFL7 expression level group, as compared with the high EGFL7 expression level group. In addition, 30 patients (86\%) in group 1 exhibited low EGFL7 expression levels. These results suggest that patients with low EGFL7 expression levels were more likely to respond well to NAC, compared with patients with high EGFL7 expression levels, indicating that EGFL7 may be a predictive marker for determining whether NAC is likely to be effective in individual patients with advanced uterine cervical cancer. 
Table III. Characteristics of the patients in the low and high EGFL7 expression groups.

\begin{tabular}{lccc}
\hline Characteristic & $\begin{array}{c}\text { Low EGFL7 } \\
\text { expression }(\leq 6)\end{array}$ & $\begin{array}{c}\text { High EGFL7 } \\
\text { expression }(\geq 8)\end{array}$ & P-value \\
\hline $\begin{array}{l}\text { No. of patients } \\
\text { Age (years) }\end{array}$ & 35 & 27 & $0.144^{\mathrm{a}}$ \\
Mean \pm SD & $48.6 \pm 12.7$ & $53.1 \pm 10.8$ & \\
Range & $24-69$ & $37-68$ & \\
FIGO stage & & & $0.251^{\mathrm{b}}$ \\
IIIA & 0 & 1 & \\
IIIB & 35 & 26 & \\
Histology & & & \\
SCC & 28 & 24 & \\
A & 6 & 2 & \\
AS & 1 & 0 & \\
Other & 0 & $1^{\mathrm{c}}$ & \\
Tumor size & $47.0 \pm 15.9$ & $54.0 \pm 17.3$ & $0.144^{\mathrm{a}}$ \\
(mm; mean \pm SD) & & & \\
\hline
\end{tabular}

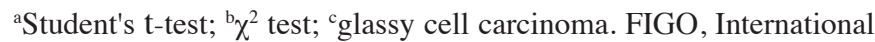
Federation of Gynecology and Obstetrics; SCC, squamous cell carcinoma; A, adenocarcinoma; AS, adenosquamous carcinoma; SD, standard deviation; EGFL7, epidermal growth factor-like domain 7.

Table IV. Number of patients with low and high EGFL7 expression levels in group $1(\mathrm{NAC}+\mathrm{OP}+\mathrm{R})$ and group $2(\mathrm{NAC}+\mathrm{R})$.

\begin{tabular}{lrrr}
\hline EGFL7 expression & NAC+OP+R & NAC+R & P-value \\
\hline Low $(\leq 6)$ & $30(86 \%)$ & $5(14 \%)$ & $<0.001^{\text {a }}$ \\
High $(\geq 8)$ & $5(19 \%)$ & $22(81 \%)$ &
\end{tabular}

${ }^{a} \chi^{2}$ test; $\mathrm{NAC}+\mathrm{OP}+\mathrm{R}$, neoadjuvant chemotherapy, surgery and radiotherapy; NAC+R, neoadjuvant chemotherapy and radiotherapy only; EGFL7, epidermal growth factor-like domain 7.

EGFL7 is a secreted signaling factor derived from endothelial cells that controls blood vessel formation (15); this protein is upregulated during angiogenesis and is associated with blood vessel lumen formation, vascular integrity and the regulation of the collective migration of endothelial cells during the blood vessel sprouting process through the restriction of their spatial distribution (17-19). In certain types of human cancer cells, EGFL7 suppresses the activation of endothelial cells and inhibits the expression of specific endothelial adhesion molecules (VCAM1 and ICAM1); it also reduces the adhesion of lymphocytes on the endothelium and consequently decreases vascular tightness (20).

The present study was conducted based on three hypotheses regarding the association between EGFL7 expression and tumor cell chemoresistance. The first hypothesis was that high expression levels of EGFL7 may have a role in the development of chemoresistance due to decreased drug delivery caused by reduced vascular integrity in tumors
Table V. Weighted scores for Snail expression levels in group $1(\mathrm{NAC}+\mathrm{OP}+\mathrm{R})$ and group $2(\mathrm{NAC}+\mathrm{R})$.

\begin{tabular}{lcc}
\hline & \multicolumn{2}{c}{ No. of patients } \\
\cline { 2 - 3 } Weighted score & NAC+OP+R $(\mathrm{n}=35)$ & NAC+R $(\mathrm{n}=27)$ \\
\hline 0 & 0 & 1 \\
1 & 6 & 0 \\
2 & 3 & 0 \\
3 & 4 & 1 \\
4 & 8 & 3 \\
6 & 7 & 0 \\
8 & 2 & 5 \\
9 & 3 & 2 \\
12 & 2 & 15 \\
Mean score & 4.71 & 9.37 \\
\hline
\end{tabular}

$\mathrm{NAC}+\mathrm{OP}+\mathrm{R}$, neoadjuvant chemotherapy, surgery and radiotherapy; $\mathrm{NAC}+\mathrm{R}$, neoadjuvant chemotherapy and radiotherapy only.

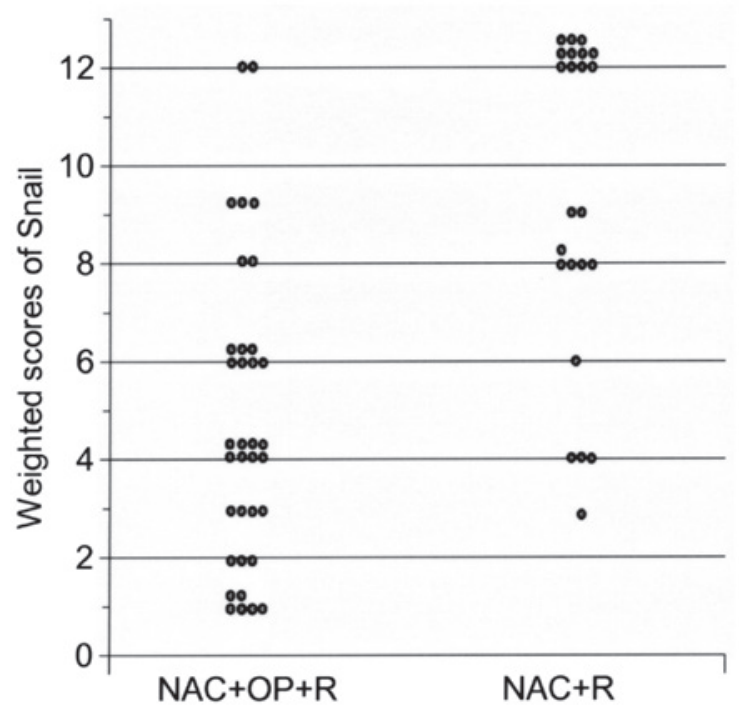

Figure 3. Weighted scores for Snail expression levels in tumor tissue samples from patients with locally advanced uterine cervical cancer. Snail expression levels were significantly higher in group $2,(\mathrm{NAC}+\mathrm{R})$ as compared with in group $1(\mathrm{NAC}+\mathrm{OP}+\mathrm{R})(\mathrm{P}<0.001$, Mann-Whitney $\mathrm{U}$ test $)$. NAC, neoadjuvant chemotherapy; OP, surgery; R, radiotherapy.

tissues. The second hypothesis was that the promotion of EMT by EGFL7 may induce the development of tumor cell resistance to chemotherapy; EMT is regulated by EGFR-mediated AKT phosphorylation induced by EGFL7, which then activates Snail and the subsequent suppression of E-cadherin transcription (27). Numerous studies have previously reported that EMT may have a function in acquired chemoresistance (28-32). The third hypothesis considered that EGFL7 may have a role in the development of tumor chemoresistance through an increased resistance to cell apoptosis induced by the activation of Snail. It has previously been reported that Snail is able to inhibit the cell cycle and confer resistance to TGF- $\beta$-induced cell death, consistent 


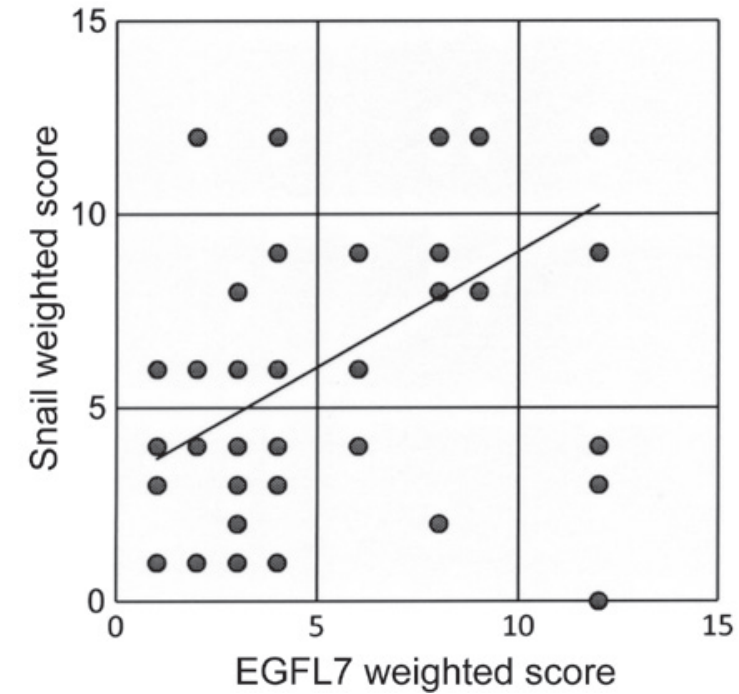

Figure 4. EGFL7 expression levels were significantly positively correlated with Snail expression levels $(r=0.56 ; \mathrm{P}<0.001)$. EGFL7, epidermal growth factor-like domain 7 .

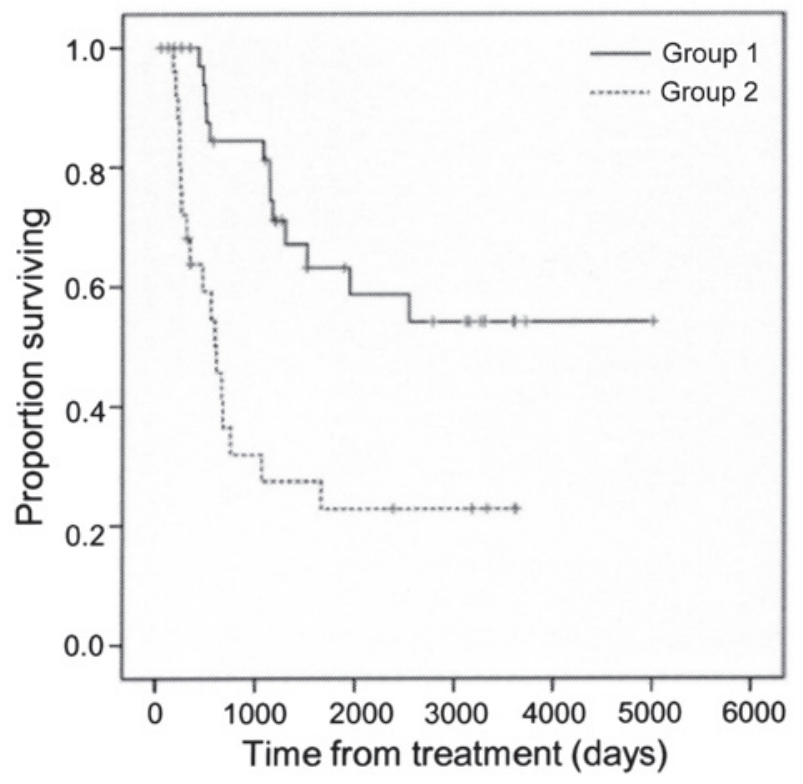

Figure 5. Overall survival rate for group $1(\mathrm{NAC}+$ surgery + radiotherapy; $\mathrm{n}=35)$ and group 2 (NAC + radiotherapy only; $\mathrm{n}=27)$. Group 1 demonstrated significantly improved overall survival, as compared with group $2(\mathrm{P}=0.001$; Kaplan-Meier and log-rank test). NAC, neoadjuvant chemotherapy.

with Snail activating the Mek/Frk and PI3K/Akt survival pathways (33). Thus, EGFL7 and Snail expression profiles were examined in the current study and a positive correlation was identified between them.

To the best of our knowledge, the present study is the first to report a significant association between EGFL7 expression levels and the response of locally advanced uterine cervical cancer to NAC. The results indicate that NAC may be more effective in patients with low EGFL7 expression levels, compared with those patients with high EGFL7 expression levels; therefore, EGFL7 expression levels may be a potential predictive marker of NAC efficacy in patients with locally advanced uterine cervical cancer. As high EGFL7 expression

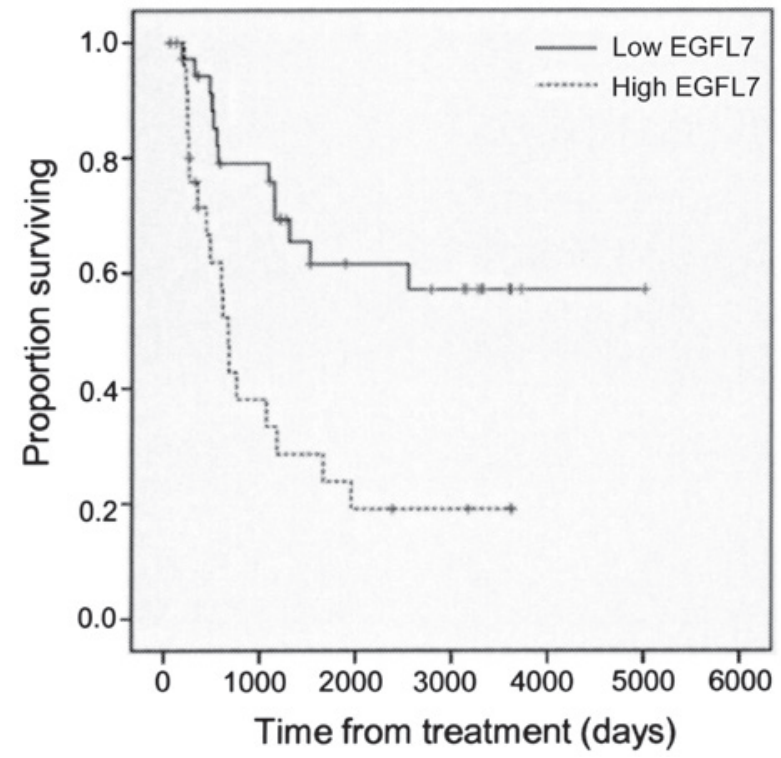

Figure 6. Overall survival rates for the low $(n=35)$ and high $(n=27)$ EGFL7 expression level groups. Significantly improved overall survival was observed in the low vs. the high EGFL7 expression level groups $(\mathrm{P}=0.001$; Kaplan-Meier and log-rank tests). EGFL7, epidermal growth factor-like domain 7.

is associated with acquired chemoresistance, tumor cells that exhibit lower EGFL7 expression may have a greater sensitivity to NAC treatment. In addition, a correlation between EGFL7 and Snail expression levels was observed These results were concordant with a previous study that reported that EGFL7 is able to positively regulate EMT by EGFR-mediated AKT phosphorylation through the activation of Snail expression (27). The results of the current study support the hypotheses that the overexpression of EGFL7 may have a role in the development of tumor chemoresistance through EMT, and increasing resistance to cell apoptosis by activating Snail expression; therefore, EGFL7 may be an effective prognostic factor regarding the efficacy of NAC treatment for locally advanced uterine cervical cancer.

Although a previous study demonstrated that surgery following NAC in locally advanced uterine cervical cancer is an effective treatment and improves the patient prognosis (7), NAC is not currently recommended as a standard treatment as, if NAC is not effective, subsequent surgery is difficult to perform and radiotherapy is required $(3,4)$; radiotherapy following the administration of chemotherapy may lead to a poorer prognosis than radiotherapy alone $(8,9)$. Therefore, it is crucial to identify novel predictive markers of NAC efficacy in patients with locally advanced uterine cervical cancer.

In summary, the results of the current study suggest that EGFL7 expression levels may be a predictive marker of NAC effectiveness for the treatment of patients with locally advanced uterine cervical cancer. Our previous study reported that the protein expression levels of B-cell lymphoma (Bcl)-extra large, Bcl-associated X-protein, mitotic arrest deficiency 2 and sirtuin 1 may be useful predictive markers of the effectiveness of NAC for patients with locally advanced uterine cervical cancer $(12,38,39)$. Using a combination of these signaling proteins, the efficacy of NAC 
may potentially be predicted for patients with locally advanced uterine cervical cancer.

\section{References}

1. Jemal A, Bray F, Center MM, Ferlay J, Ward E and Forman D: Global cancer statistics. CA Cancer J Clin 61: 69-90, 2011.

2. Pecorelli S: Revised FIGO staging for carcinoma of the vulva, cervix, and endometrium. Int J Gynaecol Obstet 105: 103-104, 2009.

3. Japan Society of Gynecologic Oncology (eds). Formulation Committee of the Treatment Guidelines for Cervical Cancer. Kanehara \& Co., Tokyo, 2011 (In Japanese).

4. National Comprehensive Cancer Network (NCCN): NCCN Clinical Practice Guidelines in Oncology: Cervical Cancer. Version II. NCCN, Fort Washington, PA 2013.

5. Morris M, Eifel PJ, Lu J, Grigsby PW, Levenback C, Stevens RE, Rotman M, Gershenson DM and Mutch DG: Pelvic radiation with concurrent chemotherapy compared with pelvic and para-aortic radiation for high-risk cervical cancer. N Engl J Med 340: 1137-1143, 1999.

6. Eifel PJ, Winter K, Morris M, Levenback C, Grigsby PW, Cooper J, Rotman M, Gershenson D and Mutch DG: Pelvic irradiation with concurrent chemotherapy versus pelvic and para-aortic irradiation for high-risk cervical cancer: An update of radiation therapy oncology group trial (RTOG) 90-01. J Clin Oncol 22: 872-880, 2004.

7. Ishiko O, Sumi T, Yasui T, Matsumoto Y, Kawamura N, Ogita S, Kamino T, Nakamura K and Yamada R: Balloon-occluded arterial infusion chemotherapy, simple total hysterectomy and radiotherapy as a useful combination-therapy for advanced cancer of the uterine cervix. Oncol Rep 7: 141-144, 2000.

8. Souhami L, Gil RA, Allan SE, Canary PC, Araújo CM, Pinto LH and Silveira TR: A randomized trial of chemotherapy followed by pelvic radiation therapy in stage IIIB carcinoma of the cervix. J Clin Oncol 9: 970-977, 1991.

9. Tattersall MH, Lorvidhaya V, Vootiprux V, Cheirsilpa A, Wong F Azhar T, Lee HP, Kang SB, Manalo A, Yen MS, et al: Randomized trial of epirubicin and cisplatin chemotherapy followed by pelvic radiation in locally advanced cervical cancer. Cervical cancer study group of the Asian Oceanian clinical oncology association. J Clin Oncol 13: 444-451, 1995.

10. Ishiko O, Sumi T, Yasui T, Matsumoto Y, Ogita S, Kaminou T, Nakamura $\mathrm{K}$ and Yamada R: Tumor marker and MR imaging criteria for evaluating the efficacy of cyclic balloon-occluded arterial infusion for advanced cancer of the uterine cervix. Oncol Rep 7: 827-830, 2000.

11. Ishiko O, Sumi T, Yoshida H, Ogita S and Yamada R: Expression of apoptosis regulatory proteins in advanced cancer of the uterine cervix after cyclic balloon-occluded arterial infusion chemotherapy. Int J Oncol 18: 1151-1155, 2001.

12. Okamoto E, Sumi T, Misugi F, Nobeyama H, Hattori K, Yoshida $H$ Matsumoto Y, Yasui T, Honda K and Ishiko O: Expression of apoptosis-related proteins in advanced uterine cervical cancer after balloon-occluded arterial infusion chemotherapy as an indicator of the efficiency of this therapy. Int J Mol Med 15: 41-47, 2005.

13. Nobeyama H, Sumi T, Misugi F, Okamoto E, Hattori K, Matsumoto Y, Yasui T, Honda K, Iwai K and Ishiko O: Association of HPV infection with prognosis after neoadjuvant chemotherapy in advanced uterine cervical cancer. Int J Mol Med 14: 101-105, 2004.

14. Benedetti Panici P, Bellati F, Manci N, Pernice M, Plotti F, Di Donato V, Calcagno M, Zullo MA, Muzii L and Angioli R: Neoadjuvant chemotherapy followed by radical surgery in patients affected by FIGO stage IVA cervical cancer. Ann Surg Oncol 14 2643-2648, 2007

15. Parker LH, Schmidt M, Jin SW, Gray AM, Beis D, Pham T, Frantz G Palmieri S, Hillan K, Stainier DY, et al: The endothelial-cell-derived secreted factor Egfl7 regulates vascular tube formation. Nature 428 : 754-758, 2014.

16. Soncin F, Mattot V, Lionneton F, Spruyt N, Lepretre F, Begue A and Stehelin D: VE-statin, an endothelial repressor of smooth muscle cell migration. EMBO J 22: 5700-5711, 2003.

17. Campagnolo L, Leahy A, Chitnis S, Koschnick S, Fitch MJ, Fallon JT, Loskutoff D, Taubman MB and Stuhlmann H: EGFL7 is a chemoattractant for endothelial cells and is up-regulated in angiogenesis and arterial injury. Am J Pathol 167: 275-284, 2005.

18. Schmidt M, Paes K, De Mazière A, Smyczek T, Yang S, Gray A, French D, Kasman I, Klumperman J, Rice DS and Ye W: EGFL7 regulates the collective migration of endothelial cells by restricting their spatial distribution. Development 134: 2913-2923, 2007.
19. Charpentier MS and Conlon FL: Cellular and molecular mechanisms underlying blood vessel lumen formation. Bioessays 36 : 251-259, 2014.

20. Delfortrie S, Pinte S, Mattot V, Samson C, Villain G, Caetano B, Lauridant-Philippin G, Baranzelli MC, Bonneterre J, Trottein F, et al: Egfl7 promotes tumor escape from immunity by repressing endothelial cell activation. Cancer Res 71: 7176-7186, 2011.

21. Jain RK: Normalization of tumor vasculature: An emerging concept in antiangiogenic therapy. Science 307: 58-62, 2005.

22. Fan C, Yang LY, Wu F, Tao YM, Liu LS, Zhang JF, He YN, Tang LL, Chen GD and Guo L: The expression of Egfl7 in human normal tissues and epithelial tumors. Int J Biol Markers 28: 71-83, 2013.

23. Díaz R, Silva J, García JM, Lorenzo Y, García V, Peña C, Rodríguez R, Muñoz C, García F, Bonilla F and Domínguez G: Deregulated expression of miR-106a predicts survival in human colon cancer patients. Genes Chromosomes Cancer 47: 794-802, 2008.

24. Zhou L, Li J, Zhao YP, Guo JC, Cui QC, Zhou WX, Zhang TP, $\mathrm{Wu} \mathrm{WM}$, You L and Shu H: Prognostic significance of epidermal growth factor-like domain 7 in pancreatic cancer. Hepatobiliary Pancreat Dis Int 13: 523-528, 2014.

25. Oh J, Park SH, Lee TS, Oh HK, Choi JH and Choi YS: High expression of epidermal growth factor-like domain 7 is correlated with poor differentiation and poor prognosis in patients with epithelial ovarian cancer. J Gynecol Oncol 25: 334-341, 2014.

26. Li JJ, Yang XM, Wang SH and Tang QL: Prognostic role of epidermal growth factor-like domain 7 protein expression in laryngeal squamous cell carcinoma. J Laryngol Otol 125: 1152-1157, 2011.

27. Luo BH, Xiong F, Wang JP, Li JH, Zhong M, Liu QL, Luo GQ, Yang XJ, Xiao N and Xie B: Epidermal growth factor-like domain-containing protein 7 (EGFL7) enhances EGF receptor-AKT signaling, epithelial-mesenchymal transition, and metastasis of gastric cancer cells. PLoS One 9: e99922, 2014.

28. Haslehurst AM, Koti M, Dharsee M, Nuin P, Evans K, Geraci J, Childs T, Chen J, Li J, Weberpals J, et al: EMT transcription factors snail and slug directly contribute to cisplatin resistance in ovarian cancer. BMC Cancer 12: 91, 2012.

29. Işeri OD, Kars MD, Arpaci F, Atalay C, Pak I and Gündüz U: Drug resistant MCF-7 cells exhibit epithelial-mesenchymal transition gene expression pattern. Biomed Pharmacother 65: 40-45, 2011.

30. Helleman J, Smid M, Jansen MP, van der Burg ME and Berns EM: Pathway analysis of gene lists associated with platinum-based chemotherapy resistance in ovarian cancer: The big picture. Gynecol Oncol 117: 170-176, 2010

31. Chang TH, Tsai MF, Su KY, Wu SG, Huang CP, Yu SL, Yu YL, Lan CC, Yang CH, Lin SB, et al: Slug confers resistance to the epidermal growth factor receptor tyrosine kinase inhibitor. Am J Respir Crit Care Med 183: 1071-1079, 2011.

32. McConkey DJ, Choi W, Marquis L, Martin F, Williams MB, Shah J, Svatek R, Das A, Adam L, Kamat A, et al: Role of epithelial-to-mesenchymal transition (EMT) in drug sensitivity and metastasis in bladder cancer. Cancer Metastasis Rev 28: 335-344, 2009.

33. Vega S, Morales AV, Ocaña OH, Valdés F, Fabregat I and Nieto MA: Snail blocks the cell cycle and confers resistance to cell death. Genes Dev 18: 1131-1143, 2004.

34. Tsuji K, Yamada R, Kawabata M, Mitsuzane K, Sato M, Iwahashi M, Kitayama S and Nakano R: Effect of balloon occluded arterial infusion of anticancer drugs on the prognosis of cervical cancer treated with radiation therapy. Int J Radiat Oncol Biol Phys 32: 1337-1345, 1995.

35. Sironi S, Belloni C, Taccagni G and DelMaschio A: Invasive cervical carcinoma: MR imaging after preoperative chemotherapy. Radiology 180: 719-722, 1991.

36. Kim KH, Lee BH, Do YS, Chin SY, Park SY, Kim BG and Jang JJ: Stage IIb cervical carcinoma: MR evaluation of effect of intraarterial chemotherapy. Radiology 192: 61-65, 1994.

37. Sinicrope FA, Ruan SB, Cleary KR, Stephens LC, Lee JJ and Levin B: bcl-2 and p53 oncoprotein expression during colorectal tumorigenesis. Cancer Res 55: 237-241, 1995.

38. Morishita M, Sumi T, Nakano Y, Teramae M, Fukuda T, Nobeyama H, Yoshida H, Matsumoto Y, Yasui T and Ishiko O: Expression of mitotic-arrest deficiency 2 predicts the efficacy of neoadjuvant chemotherapy for locally advanced uterine cervical cancer. Exp Ther Med 3: 341-346, 2012.

39. Teramae M, Fukuda T, Wada T, Kawanishi M, Imai K, Yamauchi M, Yasui T and Sumi T: Sirtuin1 expression predicts the efficacy of neoadjuvant chemotherapy for locally advanced uterine cervical cancer. Mol Clin Oncol 3: 73-78, 2015. 